\title{
INTEGRASI NILAI NILAI PANCASILA MELALUI KEGIATAN KEAGAMAAN DALAM PROGRAM JAM KE NOL
}

\author{
Rosma Fitriya \\ Guru Kelas SD Negeri 62 Palembang \\ e-mail: rosmafitria85@gmail.com
}

\begin{abstract}
A zero hour program is initiated by Disdikpora and the Government of Palembang City. This program is an effort to develop morals through religious activities held 20 minutes before the instructional process takes place. This program can also be used as a forum for introducing and practicing the value of Pancasia through religious activities. The purpose of this study was to explain the implementation of the recognition and understanding of the value of Pancasila through zero hour activities in SMK PGRI 3 of Palembang. This research was a qualitative research. The research approach used was case study. The process of collecting and extracting the data involved observation methods, interviews, and documentation. Interactive analysis model was used in analyzing the data. The results of the research were: (1) Educational institution had an important role in the effort to foster the value of Pancasila and religion to the students, (2) Zero hour program could be a medium to integrate Pancasila value with religious values, (3) The implementation of the introduction and practice of the value of Pancasila through Zero hour program at SMK PGRI 3 Palembang includeed (a) the spirit of nationality, (b) upholding unity, and (c) justice, (4) the impacts and benefits of this program could be seen through some facts. First, the students not only did became religious but their behaviors also reflected the values of honesty, selfcontrol, mutual respect, cooperation, responsibility, and discipline.
\end{abstract}

Keywords - A Zero Hour Program, The Value of Pancasila, Religious Activities.

\section{PENDAHULUAN}

Pancasila sebagai ideologi negara telah disepakati oleh the founding fathers sejak tahun 1945. Namun nilai nilai Pancasila tidak berarti telah serta merta terinternalisasi dalam diri bangsa Indonesia. Bahkan, untuk beberapa lama, Pancasila sepertinya hanya menjadi ungkapan simbolis kenegaraan tanpa jelas implementasinya, baik dalam kehidupan kenegaraan maupun kemasyarakatan (Muftuh, 2008).

Selain itu, masyarakat Indonesia, khususnya generasi muda pada era globalisasi ini mendapat pengaruh yang sangat kuat dari nilai-nilai budaya luar, sehingga mulai banyak sikap dan perilaku yang tidak sejalan dengan nilai-nilai Pancasila. Nilai nilai nasionalisme pun oleh sebagian pihak dipandang mengalami erosi pada saat ini, terutama di kalangan generasi muda (Triantoro, 2008).

Dengan demikian, sangat penting dan mendesak untuk melakukan kajian terhadap upaya pengenalan dan pengamalan nilai nilai Pancasila yang dilakukan oleh masingmasing lembaga pendidikan, baik kajian teorinya, maupun pelaksanaannya, bahkan keterlibatan masyarakat dalam pembinaan harus dijadikan bagian penting dalam upaya 
mengenalkan dan pengamalan nilai nilai Pancasila kepada generasi muda.

Ada sebagian kalangan menilai bahwa, berkembangnya paham keagamaan tidak memandang penting nasionalisme dan negara kebangsaan Indonesia. Mereka berpendapat bahwa paham keagamaan lebih memandang penting universalisme (muftuh, 2008). Pendapat ini ada benarnya, tetapi bisa juga salah. Kita ketahui bersama bahwa ideologi bangsa Indonesia dibangun melalui pengetahuan intraseptif, yang berasal dari nilai nilai agama dan nilai nilai luhur budaya bangsa. Jelas bahwa nilai nilai agama memiliki peran penting dalam merumuskan ideologi bangsa ini. Kematangan dalam bernegara juga tidak dapat lepas dari kematangan dalam memahami nilai nilai agama. Dengan memahami nilai nilai agama, maka warga negara akan memiliki karakteristik yang kuat dan dengan nilai nilai Pancasila warga negara akan memiliki rasa nasionalisme yang tinggi. Dengan demikian, jelas bahwa nilai keagamaan dan nilai Pancasila tidak dapat dipisahkan dalam kehidupan bernegara.

Beberapa karakteristik yang perlu dimiliki warganegara pada saat ini adalah: (1) kemampuan mengenal dan mendekati masalah sebagai warga masyarakat global, (2) kemampuan bekerjasama dengan orang lain dan memikul tanggung jawab atas peran atau kewajibannya dalam masyarakat, (3) kemampuan untuk memahami, menerima, dan menghormati perbedaan-perbedaan budaya, (4) kemampuan berpikir kritis dan sistematis, (5) kemauan untuk menyelesaikan konflik dengan cara damai tanpa kekerasan, (6) kemauan mengubah gaya hidup dan kebiasaan konsumtif untuk melindungi lingkungan, (7) memiliki kepekaan terhadap hak asasi dan mampu untuk mempertahankannya (seperti hak kaum wanita, minoritas etnis, dsb), dan (8) kemauan dan kemampuan berpartisipasi dalam kehidupan politik pada tingkatan lokal, nasional, dan internasional (Cogan dan Derricot, 1998). Menurut Suprapto (2014) The problems of politic, economic, social can also be completed by human resources. However, to solve the problems and deal with the high civilization competition become more advanced, Indonesia needs revitalization and strengthening strong character of human resources. One aspect that can be done to prepare for the strong human character is through education (Kristiawan, 2015). Menurut Suyatno (2010) Education is the only key that can achieve strong human resources (Kristiawan, 2015).

Menurut Suprapto (2014) Pendidikan karakter tidak sekadar mengajarkan mana yang benar dan mana yang salah, tetapi juga menanamkan kebiasaan (habituation) tentang 
hal mana yang baik. Dengan begitu, peserta didik menjadi paham (kognitif) tentang mana yang baik dan salah, mampu merasakan (afektif) nilai yang baik (loving the good/moral feeling), dan perilaku yang baik (moral action), dan biasa melakukan (psikomotor) (Kristiawan, 2016). Dengan hanya berpijak kepada nilai nilai Pancasila, karakteristik yang dikemukakan di atas tidak akan tercapai, bila tidak ditopang dengan pemahaman nilai nilai keagamaan yang kuat. Di dalam Islam, pemahaman nilai nilai agama dapat tercermin dari akhlak. Akhlak memiliki kedudukan yang sangat tinggi dan penting dalam menjalankan kehidupan bermasyarakat dan berbangsa.

Abdulah (2007) mengatakan bahwa kedudukan akhlak dalam kehidupan manusia menempati tempat yang penting, sebagai individu maupun masyarakat berbangsa, sebab jatuh bangunnya suatu masyarakat tergantung kepada bagaimana akhlaknya. Apabila akhlaknya baik, maka sejahteralah lahir dan batinnya, apabila akhlaknya rusak, maka rusaklah lahir dan batinnya. Seseorang yang memiliki ilmu pengetahuan dan tekhnologi yang maju dan disertai akhlak yang mulia, niscaya ilmu pengetahuan dan tekhnologi modern yang ia miliki itu akan dimanfaatkan sebaik-baiknya untuk kebaikan hidup manusia. Sebaliknya, orang yang memiliki ilmu pengetahuan dan tekhnologi modern namun tidak disertai dengan akhlak yang mulia, maka semuanya itu akan disalahgunakan yang akibatnya akan menimbulkan bencana di muka bumi (Nata, 2013). Hasil penelitian Ahmad dkk (2017) menyebutkan desain pembelajaran berbasis karakter di Era Masyarakat Ekonomi ASEAN salah satunya religius, yaitu membudayakan sopan santun dalam hubungan antarwarga sekolah sehingga timbul keakraban dan kekeluargaan yang harmonis.

$$
\text { Al-Jamil (1992) mengemukakan }
$$

bahwa Islam mengajarkan kehidupan yang dinamis dan progresif, menghargai akal pikiran melalui pengembangan ilmu pengetahuan dan teknologi, bersikap seimbang dalam memenuhi kebutuhan material dan spiritual, mengembangkan kepedulian sosial, menghargai waktu, sikap terbuka, demokratis, berorientasi pada kualitas, egaliter, kemitraan, antifeodalisme, mencintai kebersihan, mengutamakan persaudaraan, berakhlak mulia, dan sikap sikap positif lainnya.

Point nya adalah pemahaman mengenai tatanan nilai nilai falsafah berbangsa yaitu nilai nilai Pancasila dan pemahaman tentang nilai nilai keagamaan dapat menghasilkan tingkah laku yang ideal dalam kehidupan berbangsa dan bernegara. Presiden Jokowi mengemukakan bahwa 
Infiltrasi budaya masuk tanpa kita bisa screening dengan baik, satu satunya yang bisa kita lakukan adalah memperkuat harapan anak-anak kita dengan menanamkan nilai-nilai agama, nilai-nilai Pancasila, nilainilai budaya kita. Jangan sampai tergerus oleh budaya-budaya asing (Tribunnews, 2017).

Oleh karena itu, lembaga lembaga sekolah sebagai lembaga yang berperan penting dalam proses pendidikan bangsa, harus benar benar memahami bahwa tatanan nilai nilai agama tidak dapat dipisahkan dari nilai nilai Pancasila. Pemahaman tersebut, hendaknya selalu di tanamkan kedalam diri masyarakat sekolah sebagai pandangan hidupnya untuk menjalani kehidupan bernegara. Hakam (2011) mengemukakan bahwa kontroversi antara idealitas moral dengan realitas sosial, baik di sekolah maupun di masyarakat, menandakan perlu ditingkatkannya pembudayaan nilai moral secara integral melalui proses pendidikan. Implementasinya adalah dengan mengintegrasikan nilai nilai Pancasila kedalam setiap program sekolah, khususnya program sekolah yang bersifat keagamaan.

Salah satu program sekolah yang dapat dijadikan wadah dalam upaya menerapkan nilai nilai Pancasila melalui kegiatan keagamaan adalah program Jam Ke Nol. Program Jam Ke Nol merupakan program Pemerintah Kota Palembang yang diterapkan di sekolah melalui surat keputusan dari Disdikpora Kota Palembang pada tanggal 28 Oktober 2015. Kemudian Disdikpora Kota Palembang menginstruksikan keseluruh sekolah dari jenjang SD/MI, SMP/MTs, SMK/MA, dan SMK di Kota Palembang untuk melaksanakan program Jam Ke Nol setiap hari. Dalam program ini selama 20 menit sebelum siswa memulai pembelajaran, siswa diwajibkan untuk melaksanakan sholat dhuha, membaca ayat suci Al-Quran, dan memberikan tausiyah keislaman yang bertujuan untuk menanamkan nilai nilai keislaman. Pembinaan akhlak dilakukan melalui hal hal yang baik sebelum belajar (Disdikpora, 2015).

SMK PGRI 3 Palembang adalah salah satu SMK yang telah melaksanakan program Jam Ke Nol sejak diberikan surat edaran dari Disdikpora No 421/1-u79-a/SK 26.8/PN/2015 tentang pelaksanaan Jam Ke Nol pada jenjang Sekolah Dasar, Sekolah Mengengah Pertama, Sekolah Menengah Atas yang ada di lingkungan Disdikpora Kota Palembang. Fasilitas dan sumber daya yang masih dalam kategori belum memadai tidak menyurutkan kesadaran akanpentingnya nilai nilai Pancasia, kemauan dan kemampuan lembaga sekolah untuk merumuskan pemahaman nilai nilai 
Pancasila dan nilai nilai agama ke dalam program Jam Ke Nol, menjadi nilai tambah bagi program Jam Ke Nol yang dilaksanakan setiap hari sekolah ini. Pihak sekolah berhadap dengan program ini sekolah dapat mengasilkan output yang disiplin, religius dan memiliki keterampilan untuk bekal siswa bersaing di dalam dunia kerja.

Sesuai dengan Visi dan Misi SMK PGRI 3 Palembang yaitu : (1) visi : menciptakan tenaga kerja tingkat menengah untuk memenuhi tuntutan kebutuhan pembangunan nasional baik pada masa sekarang maupun masa yang akan datang, Palembang, 2017).

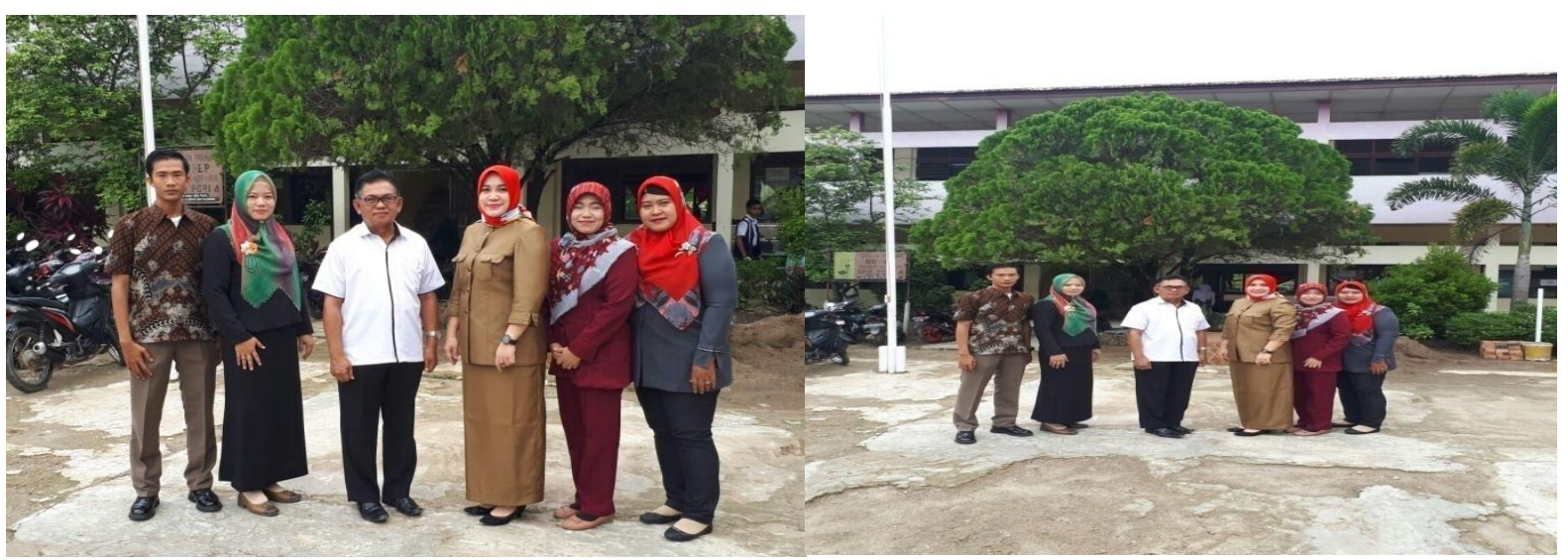

Gambar 1. SMK PGRI 3 Palembang

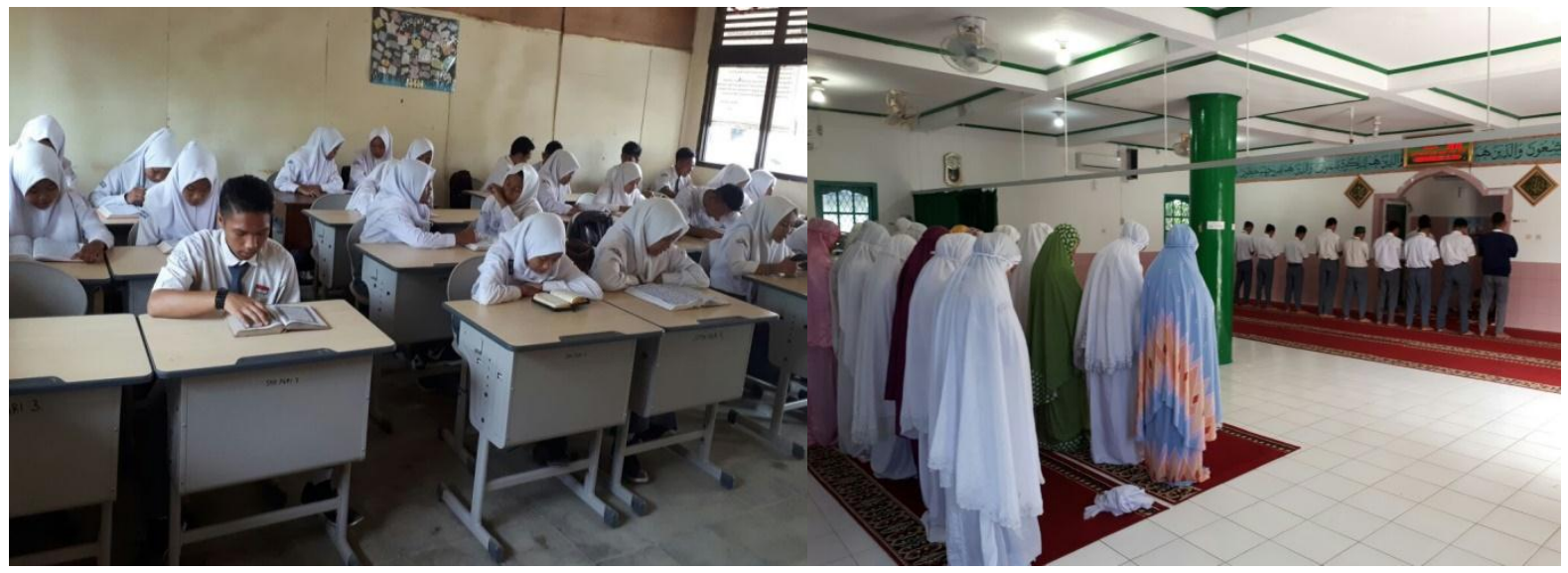

Gambar 2. Pelaksanaan Jam Ke Nol Di Ruang Sekolah dan Di Masjid Babussalam 
Program Jam Ke Nol dilaksanakan di Jam Ke Nol sebagai momentum tepat untuk SMK PGRI 3 Palembang dilaksanakan setiap menanamkan nilai nilai Pancasila kepada siswa. hari sebelum jam belajar dimulai di sekolah tersebut. waktu yang berkisar antara 15 hingga METODE PENELITIAN

20 menit sebelum memulai pelajaran di

Penelitian ini merupakan penelitian manfaatkan untuk kegiatan inti, antara lain kualitatif. Penelitian kualitatif merupakan yaitu: (1) membaca Al-Quran, (2) tausiyah, dan metode untuk mengeksplorasi dan memahami (3) sholat dhuha di masjid Babussalam yang makna yang oleh sejumlah individu atau berada di sekitar lingkungan sekolah. sekelompok orang berasal dari masalah sosial Keberadaan masjid Babussalam yang berada di atau kemanusiaan (Creswell, 2010). Pendekatan sekitar lingkungan sekolah merupakan nilai penelitian yang digunakan adalah studi kasus tambah bagi SMK PGRI 3 Palembang, untuk deskriptif. Penelitian studi kasus bermaksud melaksanakan program Jam Ke Nol di setiap untuk menemukan makna, menyelidiki proses hari sekolah. dan memperoleh pengertian dan pemahaman

Kegiatan keagamaan yang dilaksanakan yang mendalam dari individu, kelompok atau dalam program Jam Ke Nol ini dimanfaatkan situasi (Emzir, 2012). Penelitian ini melakukan oleh para pendidik di SMK PGRI 3 Palembang, studi dengan mengkaji dan mendeskripsikan untuk mengimplementasikan nilai nilai pengenalan dan pemahaman nilai nilai Pancasila Pancasila ke dalam kegiatan yang ada di dalam melalui kegiatan keagamaan dalam program program Jam Ke Nol ini, yaitu dengan Jam Ke Nol yang dilaksanakan di SMK PGRI 3 mengenalkan nilai nilai Pancasila berupa nilai Palembang. Proses pengumpulan dan nilai berkebangsaan dan persatuan serta nilai penggalian data dalam penelitian ini nilai keadilan di dalam kegiatan keagamaan menggunakan metode observasi, wawancara, yang dilaksanakan di dalam program Jam Ke dokumentasi, dan studi literature yang berkaitan Nol DI SMK PGRI 3 Palembang. Penguatan dengan penelitian ini. Teknik analisis data rasa kebangsaan melalui nilai nilai Pancasila di menggunakan teknik analisis data kualitatif, di sadari oleh pihak sekolah merupakan suatu hal mana dalam menganalisis datanya yang urgensi saat ini. Dimana saat ini nilai nilai menggunakan model analisis interaktif yaitu Pancasila hanya menjadi simbol tanpa analisis data yang dilakukan secara interaktif pengamalan bagi kaum muda saat ini. Oleh dan berlangsung secara terus menerus, terdiri karena itu, pihak sekolah menjadikan program atas pengumpulan data, reduksi data, penyajian 
data dan penarikan kesimpulan (Miles \& materi sesuai dengan jadwal yang telah di Huberman, 1984). tentukan oleh kepala sekolah SMK PGRI 3 Palembang. Untuk jadwal sholat dhuha

HASIL PENELITIAN DAN PEMBAHASAN dilakukan di masjid Babussalam, karena luas Pelaksanaan pengenalan dan ruang masjid tidak terlalu besar, maka sholat pengamalan nilai nilai Pancasila melalui dhuha dilaksanakan dengan bertahap. Selain itu, program Jam Ke Nol di SMK PGRI 3 untuk menunjang program Jam Ke Nol ini, Palembang meliputi: (1) semangat pihak sekolah menyiapkan suasana sekolah berkebangsaan, yaitu pemahaman terhadap nilai yang memungkinkan nilai-nilai tersebut nilai agama tercermin dalam rasa cinta kepada diaplikasikan dalam kehidupan persekolahan, tahah air, rasa memiliki, dan rasa dan merancang kegiatan belajar mengajar yang bertanggungjawab terhadap kesatuan Negara memungkinkan peserta didik mengaplikasikan Republik Indonesia, (2) menjunjung persatuan, nilai-nilai Pancasila dalam proses pembelajaran yaitu pemahaman nilai nilai keagamaan (Hasil Observasi Pada Tanggal 7 Oktober tercermin dalam sikap toleransi terhadap 2017). Hal ini sesuai dengan pendapat Comb perbedaan, baik itu perbedaan ras, suku, terlebih (1978) yang mengemukakan bahwa kultur lagi terhadap perbedaan agama. Kemudian tidak sekolah adalah kualitas kehidupan sekolah yang mudah terprovokasi terhadap bentuk apapun tumbuh dan berkembang berdasarkan spirit dan yang dapat memecah belah persatuan bangsa nilai-nilai tertentu yang dianut oleh sekolah. dan selalu berusaha untuk menjaga kerukunan Kualitas kehidupan sekolah tertampilkan dalam (3) keadilan, yaitu pemahaman terhadap nilai kerja Guru, Kepala Sekolah, dan tenaga nilai keagamaan berarti menjunjung tinggi hak kependidikan, serta hubungan di antara mereka, hak manusia, hak hak makhluk hidup, dan termasuk siswanya.

mementingkan kepentingan orang banyak di Program Jam Ke Nol merupakan atas kepentingan pribadi (Hasil Wawancara kegiatan keagamaan yang bertujuan untuk Tanggal 7 Oktober 2017). menempa akhlak siswa di sekolah. Akan tetapi,

Dalam proses pelaksanaan Program Jam Program ini dinilai oleh pihak sekolah dapat Ke Nol, pendidik yang melakukan tugas juga dijadikan wadah untuk mengenal dan mentoring dalam kegiatan Jam Ke Nol telah mengamalkan nilai nilai Pancasila yang mempersiapkan materi kultum terkait dengan terkandung dalam nilai nilai keagamaan. pengenalan dan pengamalan nilai nilai Menurut Maizar Bahar, S.Pd,M.Si (Kepala Pancasila. Pendidik bergantian menyampaikan Sekolah) (Hasil Wawancara Tanggal 7 Oktober 
2017), program Jam Ke Nol memang hanya kuat dalam beragama tetapi memiliki rasa seharusnya dapat menjadi momentum yang baik Nasionalisme yang tinggi (Hasil Wawancara bagi sekolah dalam upaya penanaman nilai nilai Pada Tanggal 7 Oktober 2017). Pancasila melaluli kegiatan keagamaan yang Mengintegrasikan nilai nilai Pancasila ke dalam dilaksanakan di dalam program Jam Ke Nol. nilai nilai keagamaan adalah sebuah proses Nilai nilai Pancasila dapat diperkenalkan pendewasaan bermasyarakat, dimana saat ini melalui tausiyah dan kegiatan kegiatan lain kita sedang mengalami krisis bernegara, banyak yang dilakukan di dalam kegiatan Jam Ke Nol. peristiwa peristiwa yang berkaitan dengan sara Akan tetapi, yang sangat di sayangkan adalah masih terjadi saat ini, hal ini menunjukkan lembaga sekolah masih terpaku pada konsep bahwa nilai nilai Pancasila masih harus baku pelaksanaan program ini. Sedikit sekali ditanamkan kedalam segenap bangsa terutama lembaga sekolah berinisiatif untuk kepada pemuda yang saat ini lebih suka dengan mengintegrasikan nilai nilai Pancasila ke dalam hal hal yang berbau luar (luar negeri) (Hasil kegiatan keagamaan dalam Program ini. Oleh Wawancara Pada Tanggal 7 Oktober 2017).

karena itu, program Jam Ke Nol harus dikelola

Pelaksanaan Program Jam Ke Nol di dan di rancang agar bagaimana nilai nilai SMK PGRI 3 Palembang, yang telah Pancasila dapat di integrasikan kedalam terselenggara dalam kurun waktu satu setengah kegiatan keagamaan yang ada dalam program tahun ini, dinilai telah membantu, khususnya ini. Ibarat pepatah mengatakan sambil berenang terhadap pembentukan karakter siswa melalui minum air. Dengan satu program lembaga perubahan tingkah laku siswa sehari hari di pendidikan dapat mencapai dua tujuan sekaligus sekolah. Menutut Ibnu Sabil Haq, S.Pd.I. yaitu menanamkan nilai nilai Pancasia dan nilai (pemuka masyarakat dan pengurus masjid nilai keagamaan.

Babussalam) siswa di SMK PGRI 3 Palembang,

Kebanyakan sekolah masih terpaku ke merasa antusias ketika melaksanakan praktik dalam konsep baku program ini, yaitu kegiatan sholat Dhuha dan mendengarkan tausiyah yang keagamaan, padahal di sela sela pelaksanaan disampaikan oleh ustadz. Hal ini menandakan kegiatan keagamaan, pendidik dapat telah tertanamnya nilai nilai keagamaan yang memasukkan materi nilai nilai Pancasila ke kuat di dalam diri siswa SMK PGRI 3 dalam kegiatan tersebut. Hal inilah yang Palembang. Tidak hanya itu, siswa SMK PGRI dilakukan oleh SMK PGRI 3 Palembang, SMK 3 Palembang selalu menjaga kebersihan masjid PGRI 3 Palembang merancang penuh program dan bersama sama membersikan masjid yang ini, agar dapat menghasilkan siswa yang bukan telah digunakan untuk kegiatan sekolah. Kami 
sangat mengapresiasi kegiatan ini, apalagi disela khususnya untuk bersaing didunia kerja, karena sela kegiatan, guru sering memberikan anjuran untuk bertahan di dunia kerja, tidak cukup untuk menanamkan nilai nilai Pancasila kepada hanya mengandalkan skill, akan tetapi perlu siswa. Anjuran tersebut terasa perlu di kejujuran, displin yang tinggi serta rasa sampaikan, apalagi dalam kondisi saat ini, tanggungjawab (Hasil Wawancara Pada dimana nilai nilai Pancasila tidak lagi tercermin Tanggal 10 Oktober 2017).

dari perilaku sehari hari (Hasil Wawancara Pada

Dari hasil wawancara dan hasil Tanggal 8 Oktober 2017).

observasi peneliti, maka beberapa hal yang

Disiplin yang ditunjukan oleh siswa dapat dijelaskan bahwa program Jam ke Nol SMK PGRI 3 Palembang, menunjukkan bahwa yang dilaksanakan di SMK PGRI 3 Palembang nilai nilai Pancasila, telah diamalkan oleh siswa telah dilaksanakan dengan baik oleh pihak SMK PGRI 3 Palembang. Menurut Maizar sekolah. Pihak sekolah juga telah merencanakan Bahar, S.Pd., M.Si, (Kepala Sekolah SMK dengan baik bagaimana program Jam Ke Nol ini PGRI 3 Palembang), pihak sekolah merasakan dapat menjadi wadah bagi sekolah untuk dapat dan dapat melihat bahwa terjadi perubahan yang menanamkan nilai nilai Pancasila dan nilai nilai kuat terutama pada prilaku siswa sehari-hari. keagamaan secara bersamaan. Dampak dan Berbeda dengan sebelum dilaksanakan program manafaatnya sudah dapat dilihat oleh pihak Jam Ke Nol, siswa SMK PGRI 3 Palembang sekolah setelah di laksanakannya program Jam saat ini telah menyadari bahwa mereka harus Ke Nol di SMK PGRI 3 Palembang, siswa tidak menjaga kebersihan dan kedisiplinan. Akhir hanya religius akan tetapi siswa menunjukkan akhir ini pihak sekolah bisa dikatakan sangat prilaku yang mencerminkan nilai-nilai jarang sekali memberikan intruksi untuk kejujuran, pengendalian diri, saling menjaga kebersihan lingkungan sekolah dan menghormati, kerjasama, bertanggung jawab, sekitar sekolah, rata rata siswa telah memahami dan displin. Lickona (2000) menyatakan bahwa mereka memiliki tanggung jawab beberapa nilai kebaikan yang perlu dihayati dan terhadap sekolah, hal ini yang sebenarnya kami dibiasakan dalam kehidupan peserta didik agar harapkan dari siswa, agar mereka memiliki rasa tercipta kehidupan yang harmonis di lingkungan tanggungjawab, jujur, disiplin yang tinggi, dan sekolah, dalam keluarga dan masyarakat. yang penting adalah mereka dapat menjaga Beberapa nilai itu antara lain: kejujuran, kasih kerukunan antar sesama. Apabila karakter ini sayang, pengendalian diri, saling menghargai dapat dipertahankan, maka pasti akan berguna menghormati, kerjasama, tanggung jawab, dan bagi kehidupan mereka di luar sekolah tekun. Kaelan, (2002) seluruh kedudukan dan 
fungsi Pancasila bukanlah berdiri secara sendiri oleh kematangan jiwa adalah bagaikan granat sendiri namun bilamana diikelompokkan maka hidup di tangan anak-anak yang akan akan kembali pada dua kedudukan dan fungsi membahayakan kelangsungan hidupnya Pancasila yaitu sebagai dasar filsafat Negara dan (Madjid, 2000). Oleh karena itu, sebagai pandangan hidup bangsa Indonesia. penyelenggaraan pendidikan di Indonesia

Karim (2004) mengemukakan bahwa diarahkan pada pembentukan Manusia Pancasila merupakan buah penggalian dan Indonesia Seutuhnya (MIS) yang berkualitas, perumusan dari apa yang telah ada akan mandul yakni manusia yang beriman dan taqwa jika tidak diinternalisasi dalam kehidupan terhadap Tuhan Yang Maha Esa, cerdas, pribadi yang paling pribadi. Maka Pancasila terampil, berbudi pekerti luhur, kreatif, inovatif, diharapkan benar-benar menjadi watak dan pola dan bertanggungjawab terhadap pembangunan kontras yang mencirikan pribadi Indonesia yang bangsa (Megawati, 2005).

meresapi setiap warga negaranya. Pancasila Megawangi (2010) mengemukakan diharapkan menjadi cita-cita normatif yang bahwa untuk menjadikan manusia yang cinta memasuki tulang dan daging putra putri bangsa. damai, jujur, bertanggung jawab menjaga Khotimah dan Harmanto (2016) mengemukakan lingkungan dan kualitas akhlak lainnya, adalah bahwa seiring dengan perkembangan dan dengan menciptakan manusia-manusia perubahan sosial di negara Indonesia banyak Indonesia yang batinnya hidup, yaitu yang ditemui berbagai kenakalan remaja yang mampu memilih mana yang baik dan benar, dilakukan oleh oleh siswa sekolah seperti mampu mengontrol dorongan-dorongan nafsu perkelahian antarpelajar, siswa membolos ketamakan, berpikir kritis, kreatif, beretos kerja sekolah, pelanggaran tata tertib sekolah dan tinggi, dan selalu berinisiatif untuk melakukan sebagainya. Terjadinya dekadensi nilai-nilai kebaikan, dan berusaha untuk semakin lebih Pancasila dikalangan pelajar menimbulkan baik setiap harinya. Tentu ini merupakan hal banyaknya perilaku menyimpang yang yang sulit, namun membangun manusia yang dilakukan oleh siswa. Bila tidak ada penanaman batinnya hidup mutlak diperlukan sebagai nilai-nilai Pancasila serta perhatian dari orang pondasi penting bagi terbentuknya manusiatua maka siswa akan semakin terjerumus dalam manusia yang berkarakter mulia. Pondasi permasalahan-permasalahan sosial tersebut. penting yang dikemukakan oleh Megawangi Kemudian, Majid (2000) tersebut, tidak lain adalah nilai nilai agama yang mengemukakan bahwa kemajuan ilmu dipadupadankan dengan nilai nilai Pancasila. pengetahuan dan teknologi yang tidak didahului Dengan menanamkan kedua nilai tersebut, maka 
siswa akan memiliki bekal untuk menjalani siswa. Nilai kedisiplinan dan menghargai kehidupan dunia dan kahirat.

perbedaan pendapat ditunjukkan melalui

Hasil penelitian ini di dukung oleh kegiatan rapat OSIS rutin yang dilaksanakan Mairawan (2010) dengan hasil studi pada hari rabu. Nilai kerja sama dan menunjukkan bahwa bangsa Indonesia sebagai kebersamaan dalam berorganisasi ditunjukkan warga dunia menghendaki kehidupan dalam berbagai kegiatan OSIS seperti festival berdasarkan trilogi karakter manusia Al-Barzanji, Kegiatan Isra Miraj. Perilaku siswa bermartabat, yaitu damai, mandiri, dan adil setelah mengikuti kegiatan OSIS, siswa berani untuk mencapai kehidupan yang lebih baik, mengemukakan pendapat di depan umum, lebih berbahagia lahir batin di dunia dan akhirat. percaya diri, disiplin dan sifat individualitas Implikasinya, untuk mewujudkan ke-hidupan berkurang.

yang berbahagia lahir batin di dunia dan akhirat Penelitian yang dilakukan oleh memerlukan transformasi budaya, khususnya Rahmawati, Prantiasih, Barubara (2013) dengan melalui prioritas utama pendidikan sepanjang hasil penelitian adalah: (1) Implementasi nilaihayat berdasarkan trilogi karakter manusia nilai Pancasila dalam RPP dilakukan dengan bermartabat, yaitu damai (etika), mandiri cara melihat silabus untuk menentukan nilai(logika), dan adil (estetika) bagi semua. nilai Pancasila yang sesuai dalam SK/KD, (2) Kemudian hasil penelitian yang Pada proses pelaksanaan pembelajaran dilakukan oleh Khotomah dan Harmanto (2016) Pendidikan Kewarganegaraan (PKn) belum dengan hasil dari penelitian menunjukkan tercapai secara maksimal karena pembelajaran kegiatan OSIS meliputi nilai sosial yang dengan menggunakan metode diskusi kelompok diimplementasikan melalui bakti sosial ke panti kurang berhasil dan kelas menjadi tidak asuhan yang dilaksanakan pada bulan kondusif, beberapa siswa tidak mengerjakan ramadhan, nilai religius atau nilai keagamaan tugas, serta pengelolaan kelas yang kurang yang diimplementasikan melalui kegiatan berhasil, (3) Persepsi siswa kelas VIII terhadap Anjangsana untuk mempererat tali silaturrahmi pembelajaran nilai-nilai Pancasila dalam PKn dan membaca Al-Quran, kegiatan festival Al- dapat dilihat melalui tingkah laku siswa serta Barzanji dan kegiatan Isra Miraj. Nilai cinta dapat menjelaskan arti dari nilai-nilai Pancasila tanah air di implementasikan melalui kegiatan menurut pemahaman mereka serta bisa upacara rutin hari senin, kegiatan hari bumi dan menyebutkan contoh penerapannya, (4) Faktor kegiatan memperingati hari Kartini untuk pendorong serta kendala yang dihadapi ada dua menumbuhkan rasa nasionalisme dalam diri macam yaitu berasal dari internal dan eksternal, 
(5) Upaya untuk mengatasi kendala meliputi tahah air, rasa memiliki, dan rasa bertanggung upaya internal dan upaya eksternal. jawab terhadap kesatuan Negara Republik

Dari beberapa penelitian di atas, dapat Indonesia, (2) menjunjung persatuan, yaitu dikemukakan bahwa menanamkan nilai nilai pemahaman nilai nilai keagamaan tercermin Pancasila dapat di upayakan melalui program dalam sikap toleransi terhadap perbedaan, baik sekolah. Dengan mengintegrasikan nilai-nilai itu perbedaan ras, suku, terlebih lagi terhadap Pancasila kedalam kegiataan sekolah, baik itu, perbedaan agama. Kemudian tidak mudah dalam kegiatan formal maupun ekstrakulikuler terpropokasi terhadap bentuk apapun yang yang ada di sekolah. Upaya ini tidak akan bdapat memecah belah persatuan bangsa dan terlaksana dengan baik apabila tidak di dukung selalu menjaga kerukunan antar sesama, (3) oleh seluruh stake holder sekolah. Oleh karena keadilan, yaitu pemahaman terhadap nilai nilai itu upaya penanaman nilai nilai Pancasila keagamaan berarti menjunjung tinggi hak hak melalui program sekolah harus benar-benar di manusia, hak-hak makhluk hidup, dan rencanakan dengan baik. mementingkan kepentingan orang banyak di

\section{KESIMPULAN}

Lembaga pendidikan memiliki peran penting dalam upaya menanamkan nilai nilai Pancasila dan nilai nilai keagamaan kepada siswa, salah satu cara yang dapat ditempuh adalah dengan mengintegrasikan nilai nilai Pancasila ke dalam kegiatan sekolah. Program Jam Ke Nol seharusnya dapat menjadi wadah untuk memadupadankan nilai nilai Pancasila dengan nilai nilai keagamaan. SMK PGRI 3 Palembang melihat bahwa program Jam Ke Nol merupakan momentum untuk melaksanakan hal ini melalui program Jam Ke Nol. Pelaksanaan pengenalan dan pengamalan nilai nilai Pancasila melalui program Jam Ke Nol di SMK PGRI 3 Palembang meliputi (1) semangat berkebangsaan, yaitu pemahaman terhadap nilai nilai agama tercermin dalam rasa cinta kepada atas kepentingan pribadi, (3) dampak dan manafaatnya sudah dapat dilihat oleh pihak sekolah setelah di laksanakannya program Jam Ke Nol di SMK PGRI 3 Palembang, siswa tidak hanya religius akan tetapi siswa menunjukkan prilaku yang mencerminkan nilai-nilai kejujuran, pengendalian diri, saling menghormati, kerjasama, bertanggung jawab, dan disiplin.

\section{DAFTAR PUSTAKA}

Abdullah, Yatimin, M. (2007). Studi Akhlak Dalam Persfektif Al-Qur'an. Jakarta: Amzah.

Ahmad, S., Kristiawan, M., Tobari, T., \& Suhono, S. (2017). Desain Pembelajaran SMA Plus Negeri 2 Banyuasin III Berbasis Karakter Di Era Masyarakat Ekonomi ASEAN. Iqra (Educational Journal), 2(2), 403-432. 
Al-Jamil, Abu Bakar. (1998). Mengenal Akhlak dan Etika Islam. Jakarta: Lentera Basritama.

Cogan, John J. dan Derricot, R. (1998). Citizenship for the 21st Century: An International Perspective on Education. London: Cogan Page.

Creswell, J.W (2010). Research Design Qualitative, Quantitative, and Mixed Methods Approaches. Third Edition. (diterjemahkan oleh Achmad Fawaid). Yogyakarta: Pustaka Pelajar

Comb, Arthur W. (1978). Affective Education or None at All. Values Education Journal, 4(2): 25-40.

Dinas Pendidikan dan Olahraga Kota Palembang. Surat Keputusan Dinas Pendidikan dan Olahraga Kota Palembang No 421/1-u79-a/SK 26.8/PN/2015. Tentang Pelaksanaan Jam Ke Nol Pada Setiap Jenjang Sekolah Dasar, Sekolah Menengah, dan Sekolah Atas di Wilayah Lingkungan Dinas Kota Palembang. 28 Oktober 2015.

Emzir. (2012). Metodologi Penelitian Kualitatif Analisis Data. Jakarta: Raja Grafindo Persada.

Kama Abdul Hakam. (2011). Pengembangan Model Pembudayaan Nilai-Moral dalam Pendidikan Dasar di Indonesia: Studi Kasus di Sekolah Dasar Negeri Bandungrejosari 1 Kota Malang, Jawa Timur. Sosiohumanika, 4(2): 184-159.

Kaelan. (2002). Filsafat Pancasila. Yogyakarta: Paradigma.

Karim, M. Abdul. (2004). Menggali Muatan Pancasila dalam Perspektif Islam. Yogyakarta: Surya Raya.

Khotimah, Khusnul dan Harmanto. (2016). Penanaman Nilai-Nilai Pancasila Melalui
Kegiatan Organisasi Siswa Intra Sekolah Di Man Mojosari Kabupaten Mojokerto Kajian Moral dan Kewarganegaraan. Volume 03 No 4 Tahun 2016: 1469-1484.

Khotimah, Khusnul dan Harmanto (2016). Penanaman Nilai-Nilai Pancasila Melalui Kegiatan Organisasi Siswa Intra Sekolah Di MAN Mojosari Kabupaten Mojokerto Kajian Moral dan Kewarganegaraan. Volume 03 No 4: 1469-1484.

Kristiawan, M. (2015). A Model of Educational Character in High School Al-Istiqamah Simpang Empat, West Pasaman, West Sumatera. Research Journal of Education, 1(2), 15-20.

Kristiawan, M. (2016). Telaah Revolusi Mental Dan Pendidikan Karakter Dalam Pembentukkan Sumber Daya Manusia Indonesia Yang Pandai dan Berakhlak Mulia. Ta'dib, 18(1), 13-25.

Lickona, T. (1991). Education for Character: How Our School Can Teach Respect and Responsibility. New York: Bantam Books.

Madjid, Nurcholish. (2000). Islam Doktrin dan Peradaban: Sebuah Telaah Kritis tentang Masalah Keimanan, Kemanusiaan, dan Kemodernan, Cet. IV. Jakarta: Paramadina

Maftuh, Benyamin. (2008). Internalisasi NilaiNilai Pancasila dan Nasionalisme Melalui Pendidikan Kewarganegaraan. Educationist. Vol 2 No 2: 134-144.

Mairawan, Danny. (2016). Trilogi Karakter Manusia Bermartabat Dan Implikasinya Pada Pendidikan. Jurnal Ilmu Pendidikan, Jilid 17, Nomor 3, Oktober 2010, hlm. 189194

Megawangi, Ratna. (2005). Membangun SDM Indonesia Melalui Pendidikan Holistik Berbasis Karakter. Jakarta: Direktorat Pembinaan TK dan SD [Taman Kanakkanak dan Sekolah Dasar]. 
Megawangi, Ratna. (2010). Pengembangan program pendidikan karakter Di sekolah: pengalaman sekolah karakter.

Miles, M. B. \& Huberman, A. M. (1984). Qualitative Data Analysis: A Sourcebook of Suprapto (2014). Mental revolution from New Methods. California: SAGE Publications Inc.

Nata, Abbudin. (2012). Akhlak Tasawuf. Jakarta: PT Grafindo Persada.

Rahmawati, Ita, Prantiasih, A Batubara Moch. Y. (2013). The Implementation Of Teaching A Values Of Pancasila In Citizenship Education (Civics) Subject Of Viii Grade Students At Public Junior High School 7 Malang.
Tribun News. (2017). Pentingnya Pendidikan Karakter Antisipasi Perubahan Budaya.http://www.tribunnews. com/regional/2017/09/16/

Mental revolution from
education. Unika Darma Cendikia: Surabaya.:

http://www.jawapos.com/baca/artikel/6669/ revolusi-mental-dimulai-dari-pendidikan

Suyatno (2010). Developing cultural education and national character. Article presented on National Forum by Kopertis 3 Jakarta: 